\title{
Shear Strength of Copper Joints Prepared by Low Temperature Sintering of Silver Nanoparticles
}

\author{
Zbyněk Pešina, ${ }^{1}$ Vít Vykoukal, ${ }^{2}$ Marián Palcut, ${ }^{3, *}$ and Jiř́i Sopoušek ${ }^{4}$ \\ ${ }^{1}$ Central European Institute of Technology (CEITEC BUT), Faculty of Mechanical Engineering, Brno University \\ of Technology, Brno, 61669, Czech Republic \\ ${ }^{2}$ Institute of Chemistry, Faculty of Sciences, Masaryk University, Brno, 62500, Czech Republic \\ ${ }^{3}$ Faculty of Materials Science and Technology in Trnava, Slovak University of Technology in Bratislava, Trnava, \\ 91724, Slovak Republic \\ ${ }^{4}$ Central European Institute of Technology (CEITEC MU), Masaryk University, Brno, 62500, Czech Republic
}

(received date: 2 May 2013 / accepted date: 16 July 2013 / published date: 10 January 2014)

\begin{abstract}
In this work, mechanical properties of $\mathrm{Cu}$-to-Cu joint samples prepared by low temperature sintering of $\mathrm{Ag}$ nanoparticle paste have been investigated. The silver nanopaste was prepared by a controlled thermal decomposition of an organometallic precursor. The as-synthesized Ag particles were spherical, with an average diameter of $8.5 \mathrm{~nm}$. The $\mathrm{Cu}$-to-Cu joint samples were made by placing a small amount of $\mathrm{Ag}$ nanopaste between two polished $\mathrm{Cu}$ plates and sintering at $150^{\circ} \mathrm{C}, 200^{\circ} \mathrm{C}, 220^{\circ} \mathrm{C}$ and $350^{\circ} \mathrm{C}$ in air. A normal load was applied to aid sintering. Mechanical properties were measured by imposing a uniform stress across the sample bond area and measuring the corresponding strain. The application of external load was found to have a positive effect on the material's mechanical properties. Furthermore, interestingly high values of shear strength were observed.
\end{abstract}

Keywords: Ag nanoparticles, shear strength, low-temperature sintering, lead-free solder

\section{INTRODUCTION}

Recent European Union directives have imposed restrictions on the use of hazardous substances in electrical and electronic equipment and initiated the development of leadfree alloys for soldering. ${ }^{[1]}$ Furthermore, the emergence of silicon carbide-based electronic devices, operating at high temperatures, has led to the emergence of novel, high-meltingpoint joining materials and new soldering approaches. ${ }^{[2,3]}$ For high temperature soldering, there is a relatively small number of candidates compared to low temperature solders. ${ }^{[4]}$ The most suitable alloys are Ag-, Au- and $\mathrm{Zn}$-based binary systems with $\mathrm{Sn}, \mathrm{Ge}, \mathrm{Al}$ or $\mathrm{Bi}^{[4]}$ These materials have a favorable melting temperature (Ag-Bi), relatively high strength $(\mathrm{Au}-\mathrm{Ge})$ and are easy to manufacture ( $\mathrm{Zn}-\mathrm{Al}){ }^{[4]}$ Nevertheless, challenges with respect to their poor corrosion resistance (Zn-Sn, $\mathrm{Zn}-\mathrm{Al}$ ), low conductivity (Bi-Ag) and high costs (Au-Sn, Au-Ge) limit their practical use. ${ }^{[4]}$ At present, there is no single lead-free solder alloy to cover all possible high temperature applications. As such, further research into both new materials and new joining techniques is required.

Nanomaterials are interesting candidates for soldering. ${ }^{[5]}$

*Corresponding author: marian.palcut@gmail.com CKIM and Springer
Their small particle size results in a melting point decrease due to the large surface energy of nanoparticles and high surface area to volume ratio. ${ }^{[5]}$ As such, nanoparticles can be used as interconnects in electronics packaging and assembly. Nanoscale Ag pastes are promising joining materials due to their low sintering temperature. ${ }^{[2,3]}$ These materials can be used for soldering at temperatures below $300^{\circ} \mathrm{C}^{[6]}$ Once sintered, the silver joints have high thermal and electrical conductivity and the high melting point of bulk silver $\left(960^{\circ} \mathrm{C}\right)$ which makes them suitable for high temperature operation.

In this work, the shear strength and fracture surface morphology of nanosilver-copper joints have been investigated. The silver nanoparticles were prepared by a controlled thermal decomposition of an organometallic precursor. The results obtained are compared to previously published results from different nano-Ag pastes.

\section{EXPERIMENTAL PROCEDURE}

\subsection{Nanoparticle synthesis and characterization}

Silver nanoparticles (Ag-NPs) were prepared by thermal decomposition of bis (dodecylamin) silver nitrate, $\left[\mathrm{Ag}\left(\mathrm{C}_{12} \mathrm{H}_{25} \mathrm{NH}_{2}\right)_{2}\right] \mathrm{NO}_{3}$, in air. ${ }^{[7]}$ The nanoparticles were concentrated by sedimentation in an ultracentrifuge. The freshly prepared nanoparticles were stored in a nonpolar 
solvent, either $n$-hexane or toluene. The solution was held in an ultrasonic bath for 20 minutes prior to analysis.

The nanoparticle solutions were studied by a combination of two methods: transmission electron microscopy (TEM) and dynamic light scattering (DLS). The combination of these techniques is useful since the electron microscopy provides a physical diameter of the nanoparticle while the DLS yields a hydrodynamic diameter of the solvated nanoparticle in solution. ${ }^{[8]}$ Therefore, the DLS size distribution includes the size of the stabilizing solvated shell around the nanoparticle.

Two transmission electron microscopes were employed: a scanning transmission electron microscope (STEM) Philips CM12 working with an accelerating voltage of $20-120 \mathrm{kV}$ and high resolution transmission electron microscope (HRTEM) JEOL JEM 3010, working with a $300 \mathrm{kV}$ accelerating voltage. The electron source of the STEM Philips CM12 was a W cathode whilst the Jeol microscope used an $\mathrm{LaB}_{6}$ cathode. The size of the Ag NPs was evaluated from individual images by means of SW Atlas - Morphology image analysis (TESCAN). The light scattering was measured in a glass cuvette by Zetasizer Nano ZS instrument (Malvern Instruments Ltd., Worcestershire, UK) at room temperature.

\subsection{Solder joint preparation and mechanical testing}

The $\mathrm{Cu}$ plates were etched with $\sim 2 \mathrm{~mL}$ of diluted sulphuric acid $\left(\mathrm{H}_{2} \mathrm{SO}_{4}\right)$ prior to the experiment to remove the initial oxide scale. The joint samples were prepared by placing a small amount of Ag NPs ( 10 mg) between two parallel Cu plates. The samples were placed inside a furnace and held together by a constant normal load. The effective solder joint area was $\sim 77 \mathrm{~mm}^{2}$. The effect of sample load and annealing temperature was investigated. Two sample groups were prepared. The first group was heat-treated at $350^{\circ} \mathrm{C}$ for $30 \mathrm{~min}$. The samples were held together by using a variable sample load $(1-5 \mathrm{~N})$, resulting in a normal pressure between

Table 1. Effective shear strength $\left(R_{m}\right)$, and effective Young's modulus (E) of $\mathrm{Cu} / \mathrm{Ag} / \mathrm{Cu}$ joint samples sintered with and without normal load.

\begin{tabular}{cccccc}
\hline \hline \multirow{2}{*}{$\begin{array}{c}\text { Sample } \\
\text { no. }\end{array}$} & \multicolumn{3}{c}{ Sintering conditions } & & $R_{m}$ \\
\cline { 2 - 4 }$\left({ }^{\circ} \mathrm{C}\right)$ & $\mathrm{t}(\mathrm{min})$ & $\begin{array}{c}\text { Normal } \\
\text { load }(\mathrm{kPa})\end{array}$ & $\begin{array}{c}E \\
(\mathrm{MPa})\end{array}$ & $(\mathrm{GPa})$ \\
\hline 1 & 150 & 30 & 0 & - & - \\
2 & 200 & 30 & 0 & 1.2 & 0.48 \\
3 & 220 & 30 & 0 & 3.8 & 0.38 \\
4 & 350 & 30 & 0 & 1.8 & 0.40 \\
5 & 350 & 30 & 12.7 & 2.5 & 0.55 \\
6 & 350 & 30 & 25.5 & 2.9 & 0.35 \\
$7^{*}$ & 350 & 30 & 25.5 & 1.4 & 0.30 \\
8 & 350 & 30 & 63.7 & 3.5 & 0.43 \\
\hline
\end{tabular}

${ }^{*} \mathrm{Cu}$ planes in sample no. 7 were not etched prior to joint preparation.

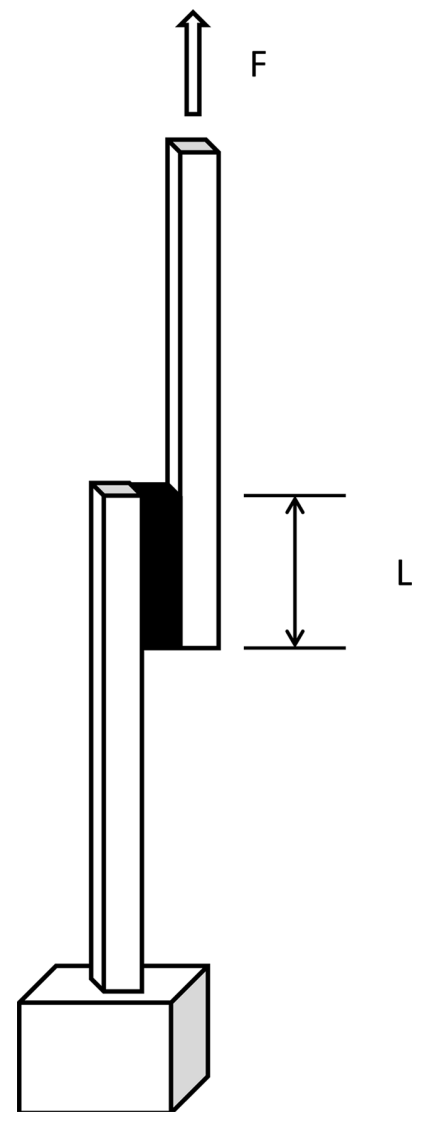

Fig. 1. Schematic overview of the shear testing experiment.

$\mathrm{Cu}$ plates $(12.7-63.7 \mathrm{kPa})$. The second group of samples was sintered at $150,200,220$ and $350^{\circ} \mathrm{C}$. The sintering conditions are detailed in Table 1. The heating and cooling rates were $15^{\circ} \mathrm{C} / \mathrm{min}$ each. An electrical heating element was used.

The $\mathrm{Cu} / \mathrm{Ag} / \mathrm{Cu}$ joint samples prepared were subjected to mechanical shear testing and the shear strength of each solder joint was measured on a Zwick Roell Z020 Testing Machine by applying forces acting along the parallel $\mathrm{Cu}$ plates. A schematic overview of the shear strength experiments is provided in Fig. 1.

\section{RESULTS AND DISCUSSION}

A microphotograph of the as-synthetized Ag NPs is shown in Fig. 2. The size distributions measured by the TEM image analysis and DLS measurements are compared in Fig. 3. The nanoparticles were evenly distributed in the studied solution. The electron microscope image shows a narrow particle size distribution, with an average particle diameter of $8.5 \mathrm{~nm}$. The DLS particle size distribution is wider compared to TEM observations. An average DLS particle diameter is $16 \mathrm{~nm}$. The DLS analysis provides a hydrodynamic diameter of the nanoparticle, which includes the size of the stabilization 


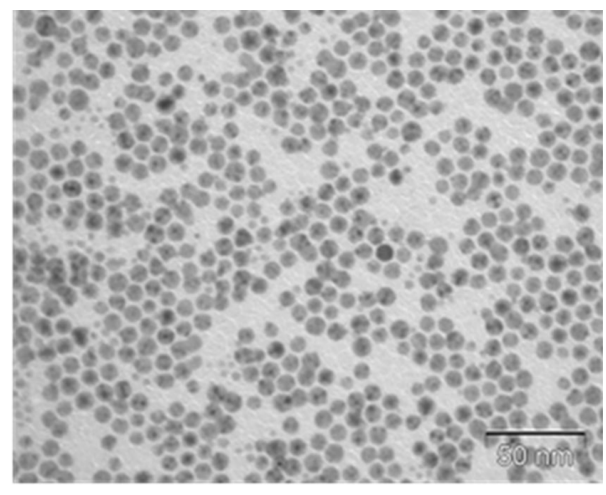

Fig. 2. Silver nanoparticles in solution (scale bar is $50 \mathrm{~nm}$ ).

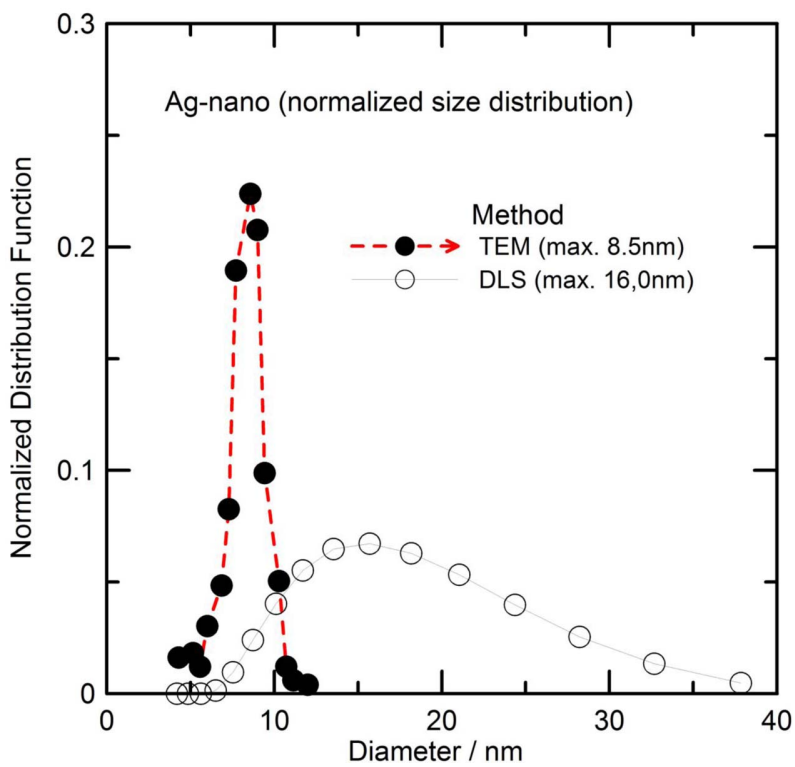

Fig. 3. Size distributions of Ag NPs studied by TEM and DLS.

organic shell and solvation layer. ${ }^{[8]}$ The analysis presented in Fig. 3 shows the size of the stabilization shell around nanoparticles is approximately $7.5 \mathrm{~nm}$.

Sample cross sections after sintering are provided in Fig. 4. The images show a well-sintered $\mathrm{Ag}$ layer. At $350^{\circ} \mathrm{C}$, oxidation of $\mathrm{Cu}$ was observed at the $\mathrm{Ag}-\mathrm{Cu}$ interface (Fig. 4(b)). The chemical composition of the copper oxide was confirmed by EDX analysis. The element profiles across the layer are provided in Fig. 4(c).

The mechanical properties of the $\mathrm{Cu} / \mathrm{Ag} / \mathrm{Cu}$ sandwich samples were studied by applying forces along the parallel $\mathrm{Cu}$ plates. The effects of sintering temperature and sample load were investigated. Graphical results are presented in Fig. 5 and 6.

Engineering stress-strain curves show interesting behavior. The curves are nearly identical before the elongation reaches $\sim 0.025 \mathrm{~mm}$ (Fig. 5). In the initial region, the engineering stress is linear and can be described by Hookes law: ${ }^{[10]}$
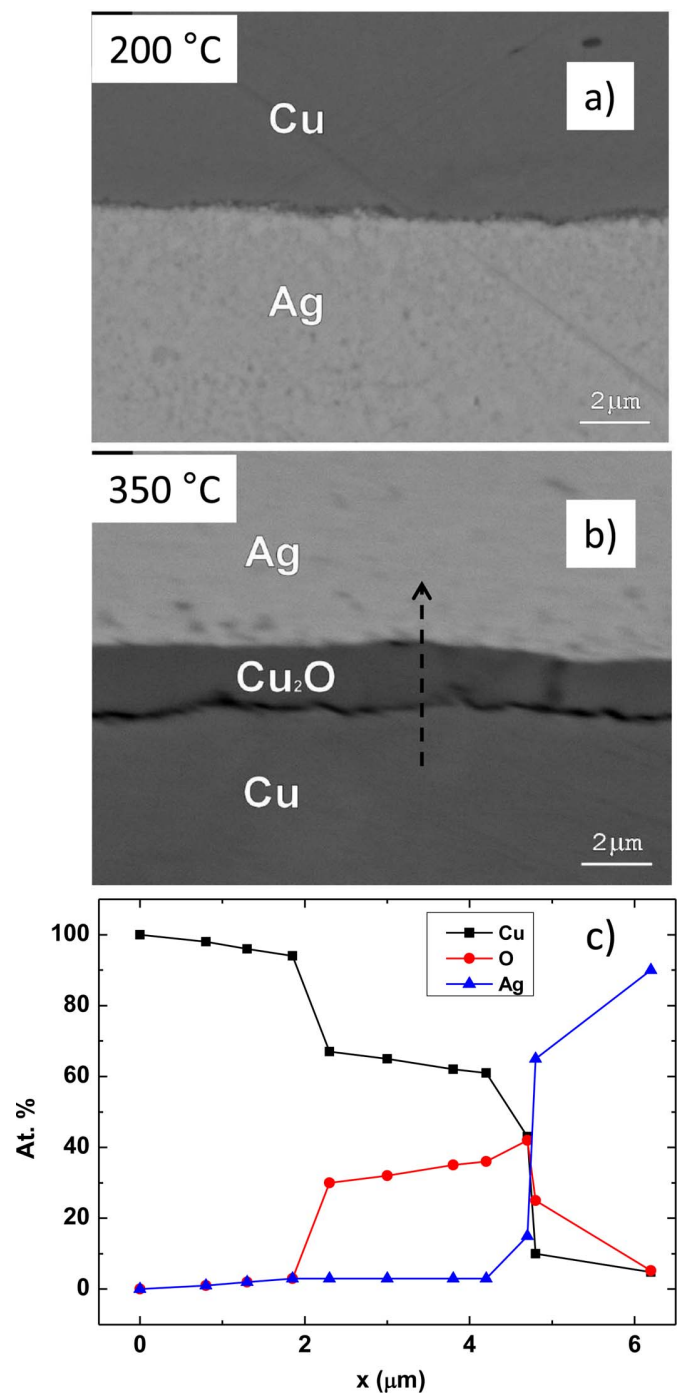

Fig. 4. Cross-sectional images of samples sintered at $200^{\circ} \mathrm{C}$ (a) and $350^{\circ} \mathrm{C}(\mathrm{b})$. An EDX element analysis is provided for sample sintered at $350^{\circ} \mathrm{C}(\mathrm{c})$.

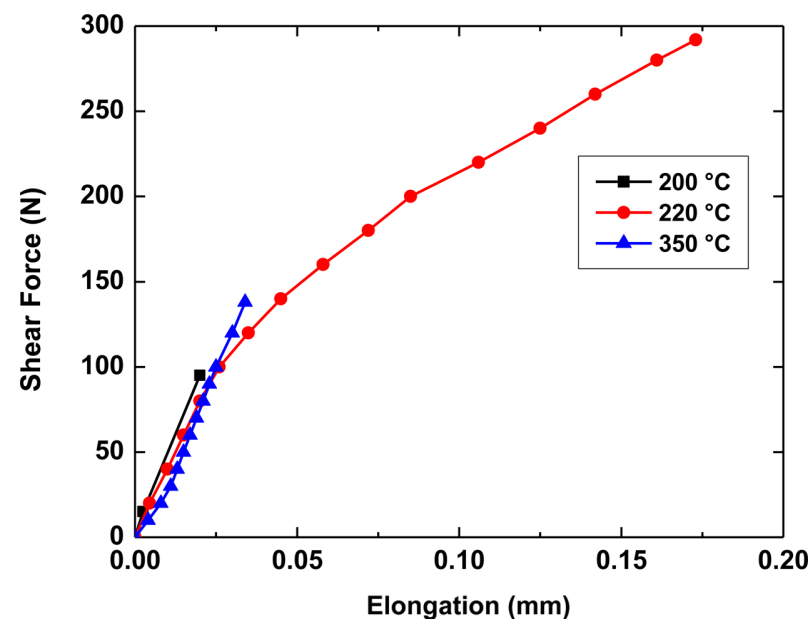

Fig. 5. Results of shear test for $\mathrm{Cu} / \mathrm{Ag} / \mathrm{Cu}$ joint samples sintered at different temperatures. 


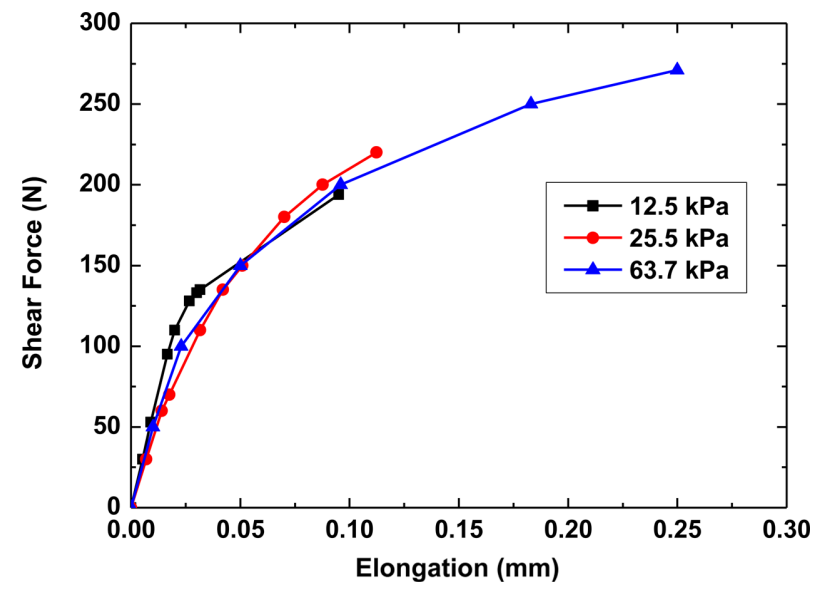

Fig. 6. Results of shear tests for $\mathrm{Cu} / \mathrm{Ag} / \mathrm{Cu}$ joint samples loaded by uniaxial pressure and sintered at $350^{\circ} \mathrm{C}$ in air.

$$
\sigma=E \varepsilon,
$$

where $\sigma$ is the engineering stress, $\varepsilon$ is the engineering strain and $E$ is the proportionality constant called Young's modulus. The engineering strain is given by the following equation

$$
\varepsilon=\Delta l / l_{0}
$$

where $\Delta l$ is the elongation and $l_{0}$ is the initial solder joint length.

Elastic moduli of differently sintered $\mathrm{Cu} / \mathrm{Ag} / \mathrm{Cu}$ sandwich samples are presented in Table 1. The evaluated Young's modulus represents an effective value. The linear dependence of $\sigma$ and $\varepsilon$ corresponds to elastic deformation. ${ }^{[10]}$ At higher stresses, plastic deformation and fracture are observed. An example of fracture surface morphology of a sample after mechanical shear testing is given in Fig. 7.

The experimental shear test results for $\mathrm{Cu} / \mathrm{Ag} / \mathrm{Cu}$ joint samples, given in Table 1, show the maximum shear strength is observed for sample No 8, prepared by low temperature sintering of $\mathrm{Ag}$ nanopaste under the highest normal load (63.7 kPa). Maximum strength of $\mathrm{Cu} / \mathrm{Ag} / \mathrm{Cu}$ joint samples, prepared without external loading, was observed for joint samples sintered at $220^{\circ} \mathrm{C}$. The results obtained for $200^{\circ} \mathrm{C}$ and $350^{\circ} \mathrm{C}$ were significantly lower (Table 1). The shear strength of the sample sintered at $150^{\circ} \mathrm{C}$ was too low to be measured. These observations indicate the shear strength is controlled by a normal load during sintering and sintering temperature. Also surface properties of Ag nanoparticles and copper plates are important. Oxide free surfaces are advantageous. The surface properties influence the total surface energy of $\mathrm{Cu} / \mathrm{Ag} \mathrm{NPs} / \mathrm{Cu}$ system during low temperature sintering. This energy dissipation is a driving force for sintering. In the following paragraphs, we shall analyze the effect of the nanoparticle sintering process on mechanical properties. We will discuss our results based on our previous sintering studies ${ }^{[9]}$ and compare the data with the investigations of other authors in the literature.

Metal nanoparticles need to be stabilized by organic molecules - dispersants - in order to avoid coalescence. The stabilization shell decreases the system's surface energy and prevents the nanoparticles from being agglomerated. Molecules such as dodecylamine (here coordinated to Ag core during Ag NPs synthesis) consist of a polar head and hydrophobic tail. The polar part is attached to metal core. The hydrophobic tail is oriented towards the outer solvent. The interaction between dispersant and metal nanocore is presented in Fig. 8.

Fast and reliable organic burnout is crucial for nanoparticle sintering. ${ }^{[2,9,11,12]}$ The starting temperature of nanoparticle sintering is controlled by solvent evaporation and organic component burnout. The vaporization of the liquid phase and organic shell decomposition have been reported to occur at temperatures close to $150^{\circ} \mathrm{C} .^{[11,12]}$ The sintering of silver nanoparticles takes place at temperatures above $170^{\circ} \mathrm{C}$ and is

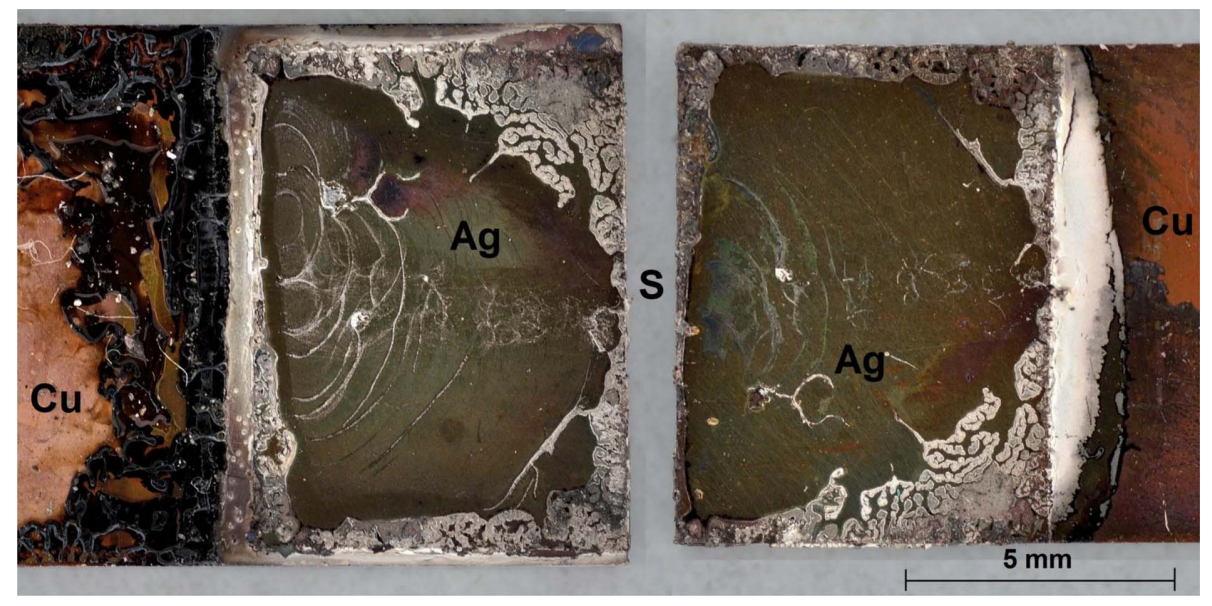

Fig. 7. Fracture surface morphology of an $\mathrm{Cu} / \mathrm{Ag} / \mathrm{Cu}$ sample $\left(\mathrm{No} 3,220^{\circ} \mathrm{C} / 30 \mathrm{~min}\right.$ ) after mechanical testing. Labels in the figure have the following meaning: $\mathrm{Cu}=$ copper plate, $\mathrm{Ag}=$ bonded area, $\mathrm{S}=$ center of symmetry. 


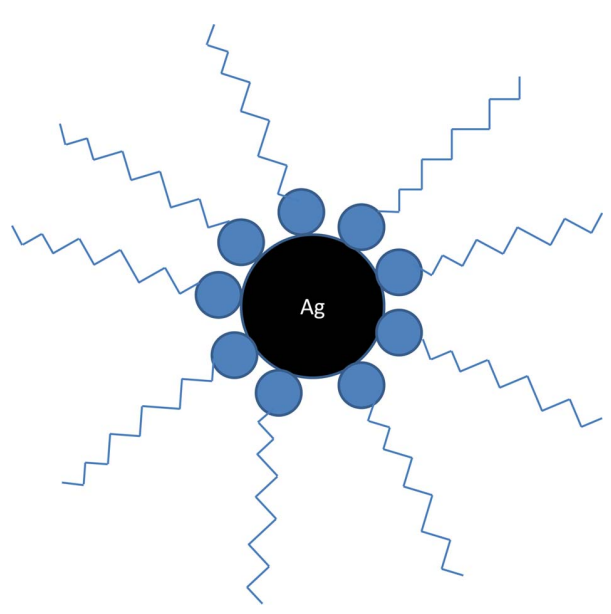

Fig. 8. Role of dispersant in nanoparticle stabilization.

practically finished at $210^{\circ} \mathrm{C}{ }^{[9]}$ Higher temperatures favor the sintering process. A drawback is the undesirable oxidation of copper. ${ }^{[9]}$ Therefore, the temperature of $220^{\circ} \mathrm{C}$ seems to be the optimum for materials densification. Ag layers prepared at $150^{\circ} \mathrm{C}$ and $200^{\circ} \mathrm{C}$ were probably not fully sintered. As such, they had a lower shear strength compared to samples prepared at $220^{\circ} \mathrm{C}$. The $\mathrm{Ag}$ layer prepared at $350^{\circ} \mathrm{C}$ was more sintered but had a lower shear strength value compared to sample prepared at $220^{\circ} \mathrm{C}$. This was probably a result of copper oxidation, leading to mechanical destabilization. A copper oxide layer was observed in samples sintered at higher temperatures (Fig. 4).

The external pressure applied during sintering had a positive effect on the shear strength (Table 1). The applied pressure increases the average number of contacts between $\mathrm{Ag}$ nanoparticles. As a consequence, the diffusion length increases leading to a higher sintering rate. The threshold pressure is given by several factors, including particle size of Ag NPs. ${ }^{[2]}$ The effect of external pressure on shear strength of joints prepared using Ag NPs was investigated in a pilot study. ${ }^{[3]}$ It has been reported that a pressure of $5 \mathrm{MPa}$ led to a 4-fold increase in shear strength compared to pressure-less bonding. ${ }^{[3]}$ The present study shows that considerably smaller pressures can be applied to enhance the materials' mechanical properties.

Pressure-assisted sintering is of great benefit during production of large scale solder joints (bonding area $>10 \mathrm{~mm}^{2}$ ). It has been observed that Ag NPs shear strength significantly drops with increasing interconnect area ${ }^{[13]}$ The effect is probably related to incomplete sintering at the center of a large bonding area. The sintering of large interconnection areas produces higher pore ratios as the exhaust gas molecules are unable to escape from the center of a large solder joint. ${ }^{[13]}$ The external pressure helps nanoparticle sintering and increases the sample sintering rate. The bonding area of our samples was close to $0.7 \mathrm{~cm}^{2}$. The observed shear strength values were high and comparable to those in ref. ${ }^{[13]}$ where significantly smaller samples were investigated $\left(0.2 \mathrm{~cm}^{2}\right)$. The pressure-assisted sintering employed in the present study has led to a substantial improvement of the Ag NPs shear strength.

\section{CONCLUSIONS}

In this paper, the shear strength of $\mathrm{Cu}$-to-Cu joint samples interconnected by a low-temperature sintered $\mathrm{Ag}$ nanopaste has been studied. Maximum shear strength was observed for samples sintered at $220^{\circ} \mathrm{C}$. External loads, applied during sample sintering, were found to have a positive effect on shear strength. The highest shear strength was observed for samples loaded with an external pressure of $63.7 \mathrm{kPa}$ during sintering. In conclusion, Ag NPs could be an interesting lead-free candidate for joining large scale $\left(\geq 10 \mathrm{~mm}^{2}\right) \mathrm{Cu}$ chips in high-temperature electronic devices.

\section{ACKNOWLEDGEMENTS}

Dr. David S. Wragg is thanked for his careful proofreading of the manuscript. This project was financially supported through grants no. CEITEC MU CZ.1.05/1.1.00/ 02.0068 and VEGA $1 / 0339 / 11$. A preliminary version of this work was presented at $2^{\text {nd }}$ QNano Integrating Conference in Prague (27 February 2013 - 1 March 2013) [14]. We thank the participants for fruitful discussions.

\section{REFERENCES}

1. A. Kroupa, D Andersson, N. Hoo J. Pearce, A. Watson, A. Dinsdale, and S. Mucklejohn, J. Mater. Eng. Perform. 21, 629 (2012).

2. K. S. Siow, J. Alloy. Compd. 514, 6 (2012).

3. T. G. Lei, J. N. Calata, G.-Q. Lu, X. Chen, and S. Luo, IEEE Trans. Compon. Pack. Technol. 33, 98 (2010).

4. G. Zeng, S. McDonald, and K. Nogita, Microelectron. Reliab. 52, 1306 (2012).

5. M. Maruyama, R. Matsubayashi, H. Iwakuro, S. Isoda, and T. Komatsu, Appl. Phys. A 93, 467 (2008).

6. J. Yan, G. Zou, A.-P. Wu, J. Ren, J. Yan, A. Hu, and Y. Zhou, Scripta Mater. 66, 582 (2012).

7. J. Bursik, V. Bursikova, Z. Pesina, and J. Sopousek, Chem. Listy 106, 390 (2012).

8. A. M. Collins, Nanotechnology Cookbook, Practical, Reliable and Jargon-free Experimental Procedures, p. 17, Elsevier, Oxford, U.K. (2012).

9. J. Sopousek, J. Bursik, J. Zalesak, and Z. Pesina, J. Min. Metall. B 48, 63 (2012).

10. H. Ma and J. C. Suhling, J. Mater. Sci. 44, 1141 (2009).

11. H. Alarifi, A. Hu, M. Yavuz, and Y. N. Zhou, J. Electron. Mater. 40, 1394 (2011). 
12. G. Zou, J. Yan, F. Mu, A. Wu, J. Ren, A. Hu, and Y. N. Zhou, The Open Surf. Sci. J. 3, 70 (2011).

13. K. Qi, X. Chen, and G.-Q. Lu, Solder. Surf. Mt. Technol. 20, 8 (2008).

14.Z. Pesina, V. Vykoukal, M. Palcut, and J. Sopousek,
Abstract book of the $2^{\text {nd }}$ QNano Integrating Conference "Quality in Nanosafety Assessment - Driving Best Practice and Innovation, p. 89, IMG, Prague, Czech Republic (2013) 